\title{
EMRO: Una Herramienta de Evaluación de los Mitos Románticos
}

\author{
ROMS: An Evaluation Tool for Romantic Myths
}

\author{
Yosué Piñeiro ${ }^{1}$, Raúl Piñuela ${ }^{2}$ y Carlos Yela $^{3}$
}

\begin{abstract}
Resumen
Es amplia la literatura que vincula los mitos románticos con la satisfacción/insatisfacción y la violencia en la pareja. Aun así, se echan en falta más estudios empíricos que analicen esta relación e instrumentos que evalúen una taxonomía amplia de mitos. Por ello se expone un listado de 33 mitos románticos, y se administra un cuestionario para su evaluación a una muestra de 439 sujetos. Se aporta una escala de 33 ítems, y un modelo factorial de cuatro factores (Posesión, Abnegación, Romanticismo y Tradición) y 31 ítems. Se obtiene una adecuada validez estructural, de criterio y óptimos valores de fiabilidad. Los análisis de regresión sugieren que la Posesión podría ser un predictor significativo del maltrato ejercido, mientras que la Tradición podría predecir la satisfacción en la pareja. En definitiva, se presenta un amplio listado de mitos (el más extenso que se ha localizado) y una escala con adecuadas propiedades psicométricas.
\end{abstract}

Palabras clave: mitos románticos, violencia, satisfacción, psicometría

\begin{abstract}
In spite of the existence of references linking romantic myths with satisfaction/dissatisfaction and partner violence, there is a lack of empirical studies that analyze this link as well as tools to assess a broad taxonomy of myths. Thus, this paper proposes a list of 33 romantic myths assessed through a survey provided to a sample of 439 individuals. Additionally, the paper introduces a 33-item scale and a 31-item model composed of four factors (Possession, Abnegation, Romanticism, and Tradition). As a result, the paper concludes on an adequate structural validity and criterion, with optimal reliability values. Regression analyses suggest that Possession could be a significant predictor of violence, while Tradition could predict partner satisfaction. In sum, the paper introduces a broad list of myths (the most extensive that has been identified) and a scale of accurate psychometric features.
\end{abstract}

Keywords: romantic myths, violence, satisfaction, psychometrics

\footnotetext{
${ }^{1}$ Máster en Psicología Social. Doctorando en Psicología. Universidad Complutense de Madrid. Facultad Psicología. Carretera de Húmera, s/n. C.P: 28223. Campus de Somosaguas, Madrid, España. Tel.: +34 91394 2966. Correo: yosuepin@ucm.es

${ }^{2}$ Doctor en Psicología. Facultad Psicología. Carretera de Húmera, s/n. C.P: 28223. Campus de Somosaguas, Madrid, España. Tel.: +34 91 394 3036. Correo: rpinuela@psi.ucm.es

${ }^{3}$ Doctor en Psicología. Facultad Psicología (Despacho 2306-C). Carretera de Húmera, s/n. C.P: 28223. Campus de Somosaguas, Madrid, España. Tel.: +34913942966. Correo: carlosyela@psi.ucm.es

Revista Iberoamericana de Diagnóstico y Evaluación - e Avaliação Psicológica. RIDEP · No62 · Vol.1 · 137-153 2022 ISSN: 1135-3848 print /2183-6051online
} 


\section{Introducción}

Los mitos románticos son definidos como un "conjunto de creencias socialmente compartidas sobre la supuesta verdadera naturaleza del amor" (Yela, 2003, p.264), y que comparten el hecho de ser, en mayor o menor medida, irrealizables, absurdas, ilógicas, imposibles, imprecisas, incorrectas y/o problemáticas (Yela, 2000; 2003). Creer en un mito es adherirse a un mandato (todo lo que no se base en estas falacias románticas no sería "verdadero amor"), pero lo cierto es que la realidad nunca será lo que expresa el mito, por lo que amar "de verdad" siguiendo estas creencias sería imposible. En esta línea, Herrera (2015) señala que vivimos en una cultura con mucho romanticismo, pero poco amor.

El amor romántico refleja cierta tendencia a amar la ausencia, el obstáculo, lo imposible (Sanpedro, 2005), así como a considerar que la felicidad depende del amor (y la pareja) y no de uno mismo (Herrera, 2015). Esto sumado a que es común evitar racionalizar el amor para no quitarle "magia" (Vasallo, 2015), puede convertir a la pareja en el espacio en el que "todo es apto" ("en el amor y en la guerra todo vale"), donde es más relevante el impulso que la razón, y donde se considera que el amor podría con todo (sin aceptar que una relación se termina, soportando un sufrimiento innecesario en la pareja...).

En los últimos años emerge cierta literatura que relaciona el concepto de amor (y mito) romántico con la violencia en la pareja (generalmente presentando un enfoque de género). Dicha relación se basaría en: la influencia de los celos, el control, la posesión (Bosch et al., 2013; González Ortega et al., 2008; Papp et al., 2017; Quinteros \& Carbajosa, 2008) una importancia extrema dada a la fidelidad (Zamora et al., 2012); la dependencia emocional (García \& Casado, 2010; Quinteros \& Carbajosa, 2008; Zamora et al., 2012); la idea de que se debe luchar por amor, que este es el centro de la vida de la mujer y que la relación no funcione es un fracaso personal para ellas (Chung 2005; Ferrer \& Bosch, 2013; Sanpedro, 2005; Wood, 2001); la idealización de la pareja y que el amor todo lo puede, manteniendo a la mujer en la relación de maltrato (Ferrer \& Bosch, 2013); la creencia de que amar supone complacer en todo a la pareja y perdonar en nombre del amor, en mayor medida desde el sacrificio femenino (García \& Casado, 2010; Wood, 2001; Zamora et al., 2012); considerar el amor como única fuente de felicidad, o lo que da sentido a la vida (Bosch et al., 2013; Quinteros \& Carbajosa, 2008); el hombre visto como dominante, independiente y conquistador, y la mujer como sumisa, dependiente y obediente (Bosch et al., 2007; Ferrer \& Bosch, 2013); la idea de que no existe amor sin conflicto ni sufrimiento, mitificándose el suicidio, el chantaje emocional y la violencia por amor (Herrera, 2019).

Por otra parte, el número de estudios empíricos localizados que relacionan la violencia con escalas de mitos románticos en población mayor de edad (generalmente con un enfoque de género), es reducido (Bonilla-Algovia \& RivasRivero, 2019; Borrajo et al., 2015; Bosch et al., 2007; Cruz, 2018; Ferrer et al., 2010; Lelaurain et al., 2018; Papp et al., 2017; Sharpe \& Taylor, 1999) y pocos trabajos relacionan los mitos con medidas referentes a conductas de violencia en la pareja (Borrajo et al., 2015; Cruz, 2018; Papp et al., 2017; Sharpe \& Taylor, 1999). La evidencia empírica suele referir una relación positiva entre las conductas de violencia y los mitos románticos (aunque bastante baja), y positiva y algo más elevada entre los mitos y culpar a la víctima en la agresión y exonerar al agresor. Aun así, no suele diferenciar entre los diferentes mitos románticos y se basa en medidas que incluyen un número de mitos bastante reducido.

Esta vinculación entre el amor y la violencia se enmarcaría en una estructura desigual de género y sexista (e.g., Bosch et al., 2007) que restringe a la mujer al mundo de los afectos, el ámbito privado y la sumisión (Bergara et al., 2008; Bosch et al., 2013), y al hombre a lo público, el control, el poder y la dominancia (Bergara et al., 2008; Chafetz, 1975). En este sentido, dos variables clave desencadenantes de la violencia de género en la pareja serían: el sexismo, (e.g., Bosch et al., 2013) desde las creencias erróneas sobre los roles de género y la inferioridad femenina (Echeburúa \& FernándezMontalvo, 1997) y la legitimación de la violencia (Echeburúa \& Fernández-Montalvo, 1997).

Por otro lado, que el amor (y la relación de pareja) es una variable que influye en la satisfacción vital está más que demostrado (e.g., 
Tabla 1. Instrumentos de investigación sobre Mitos Románticos

\begin{tabular}{|c|c|c|c|c|c|}
\hline Autor & $\mathrm{N}$ & Factores & I & IR & $\alpha$ \\
\hline $\begin{array}{l}\text { Knox y Sporakowski } \\
\text { (1968) }\end{array}$ & 200 & No presenta análisis factorial & 25 & $1-5$ & - \\
\hline $\begin{array}{l}\text { Hinkle y Sporakowski } \\
\text { (1975) }\end{array}$ & 234 & $\begin{array}{l}3 \text { ( } 3 \text { mitos): Tradicionalismo, omnipotencia e } \\
\text { irracionalidad }\end{array}$ & 25 & $1-5$ & - \\
\hline Sprecher y Metts (1989) & 730 & $\begin{array}{l}4 \text { (4 mitos): "El amor encuentra un camino", "Uno y } \\
\text { sólo uno", "Idealización" y "Amor a primera vista" }\end{array}$ & 15 & $1-7$ & .81 \\
\hline Barrón et al. (1999) & 1942 & $\begin{array}{l}\text { No presenta análisis factorial. Analiza } 8 \text { mitos } \\
\text { románticos }\end{array}$ & 8 & $1-5$ & - \\
\hline Bosch et al. (2007) & 1351 & $\begin{array}{l}2 \text { factores: Idealización del amor ( } 6 \text { mitos }) \text { y } \\
\text { vinculación amor-maltrato ( } 1 \text { mito) }\end{array}$ & 10 & $1-5$ & .51 \\
\hline Rodríguez et al. (2013) & 800 & $\begin{array}{l}\text { 2: Idealización del amor (4 mitos) y vinculación } \\
\text { amor-maltrato ( } 1 \text { mito) }\end{array}$ & 7 & $1-5$ & $.65 / .78$ \\
\hline
\end{tabular}

Nota. Fuente: Elaboración propia. I: Ítems; IR: Intervalo de Respuesta.

Argyle, 1987). Aun así, no se encuentra suficiente evidencia empírica en lo concerniente a la relación entre los mitos románticos y la satisfacción en la pareja.

En esta línea, la argumentación teórica y la evidencia empírica es poco concluyente (y ambivalente) en lo tocante a la relación entre la creencia de las personas en los mitos y su nivel de satisfacción con la relación amorosa (Barrón et al., 1999; Ferrer et al., 2010; Sprecher \& Metts, 1999; Vannier \& O’Sullivan, 2017; Yela, 2000; 2003). Parte de esta bibliografía no presenta datos empíricos que vinculen los mitos y la satisfacción en la pareja (Barrón et al., 1999; Yela, 2000; 2003). Sólo tres estudios de las fuentes nombradas emplean escalas específicas de mitos románticos, y presentan datos empíricos que señalan una relación directa y significativa entre varios mitos románticos y la satisfacción en la pareja (Ferrer et al., 2010; Sprecher \& Metts, 1999; Vannier \& O'Sullivan, 2017). Es destacable también que los resultados de Vannier y O'Sullivan (2017) apuntan en la misma dirección que los estudios de Ferrer et al. (2010) y Sprecher y Metts (1999), mientras que Barrón et al. (1999) y Yela (2000; 2003) se refieren el impacto negativo de los mitos románticos en la satisfacción de pareja. Esta ambivalencia hace necesario su estudio en mayor profundidad, desde una clasificación de mitos amplia que no se recoge en los trabajos nombrados.

Conocer de manera amplia qué mitos románticos nos definen podría ayudar a deshacernos de estas creencias irreales, ubicar su origen y relacionarlas con diversas variables de interés psicológico (apego, comunicación en la pareja...). Ello favorecería la promoción de modelos de amor más sanos en diversos ámbitos: educación formal, educación intrafamiliar, medios de comunicación de masas, terapia de pareja, prevención de violencia de género... En conexión con todo lo anterior, se considera imprescindible seguir estudiando dos problemáticas muy relevantes conectadas con los mitos románticos: la (in)satisfacción (como problema individual) y la violencia de género (como problema social) en la pareja. Por todo lo cual aparece como necesario diferenciar qué mitos románticos son perjudiciales en la relación de pareja, bajo el respaldo de una investigación empírica.

Para poder realizar dicha labor, se requiere una taxonomía precisa y amplia de mitos románticos y escalas que los evalúen. En la Tabla 1 se pueden observar los principales instrumentos (y estudios psicométricos) localizados referentes al análisis de los mitos románticos. De ellos aportan datos de validez estructural los trabajos de Hinkle y Sporakowski (1975), Sprecher y Metts (1989), Bosch et al. (2007) y Rodríguez et al. (2013). Se echan en falta escalas que engloben un mayor número de mitos románticos.

En consonancia con todo lo señalado, los objetivos de este estudio son los siguientes:

a) Generar un listado amplio y actualizado de mitos románticos, fruto de una amplia revisión bibliográfica.

b) Desarrollar un instrumento de evaluación de los mitos románticos con características 
psicométricas aptas, útiles para la investigación y la aplicación.

c) Analizar en qué medida la aceptación de determinados mitos románticos se relaciona con variables como la satisfacción en la relación, y la presencia y legitimación de la violencia en la pareja.

En relación al primer objetivo, se parte de la clasificación de 10 mitos románticos descritos en Yela (2000; 2003): media naranja, exclusividade, matrimonio-convivencia, omnipotência, perdurabilidad, fidelidad, libre albedrío, equivalencia, celos y emparejamiento. Por otra parte, se lleva a cabo una revisión bibliográfica de las principales fuentes encontradas sobre el amor romántico (e.g., Bosch et al., 2007; Bosch et al., 2013; Ferreira, 1995; Fundación Mujeres, 2011; Herrera, 2019; Knox \& Sporakowski, 1968; Sprecher \& Metts, 1989; Tenorio, 2012; Yela, 2000; 2003), con lo que se proponen otros 23 mitos: amor eterno, cambio, unicidad, ambivalencia romántica, flechazo, irracionalidad, amor perfecto, sentido vital, magia romántica, complementariedad, castidad, pecado, príncipe azul, cenicienta, vínculo amor-sexualidad, Don Juan, macho dominante, entrega incondicional, propiedad, exigencia máxima, sacrificio, perdón absoluto, disponibilidad inmediata.

Para cumplir el segundo objetivo (elaborar un instrumento de investigación sobre mitos románticos), se crea una escala que recoge los mitos románticos mencionados, presentando así la gran amplitud y complejidad del concepto. También se propone un modelo factorial desde la teoría relativa al amor romántico (y sus mitos):

-Posesión: Amor controlador y celoso. Engloba aquellos mitos vinculados con los celos, la posesión y el control, así como la necesidad de la pareja para dar sentido a la vida y el temor a su pérdida. Muestra una notable diferencia de poder de género (sexismo), en torno al modelo de masculinidad hegemónica occidental en el amor: un hombre dominante, agresivo, controlador, que se relaciona con el príncipe azul y el Don Juan (Chafetz, 1975; Fundación Mujeres, 2011; Herrera, 2019); y la mujer que ha de ser cuidada y protegida (Ferrer \& Bosch, 2013), así como subordinada al hombre en el amor, ideas muy criticadas en la literatura científica en la actualidad (e.g., Bergara et al., 2008; Bosch et al.,
2013). Engloba varios mitos referentes a dos variables fuertemente conectadas con la violencia de género en la pareja: los celos y el sexismo (Bosch et al., 2013; González Ortega et al., 2008; Papp et al., 2017), las cuales suelen definir al hombre agresor (Quinteros \& Carbajosa, 2008). El factor se basa en el amor Manía de John Allan Lee (1973; 1976).

-Abnegación: Amor de entrega y renuncia extrema. Hace referencia a un conjunto de mitos vinculados al esfuerzo, el apoyo y la entrega en nombre de la pareja de manera extrema, como síntomas de amor verdadero. Se basa en que el amor debe conllevar renuncia (tiempo, intimidad, hobbies, espacios...) para vincularse con la otra persona, agradando a la pareja y anteponiendo el vínculo. Al responder a un mito (ejecutándose la entrega en nombre del amor verdadero, y no bajo una auténtica elección personal), esta renuncia se convierte en una obligación, sin que tenga por qué estar sujeto a un verdadero deseo o una tendencia altruista (desinteresada). Existiría así una gran exigencia hacia uno mismo, pudiendo también esperar (o hasta exigir) la entrega por parte de la pareja como muestra de su amor verdadero. Se relacionaría con el sacrificio cristiano (De Rougemont, 1972) y la fusión con el otro en la pareja (Solomon, 1988). El factor se inspira en el amor Ágape de John Allan Lee $(1973 ; 1976)$.

-Romanticismo: Amor fantástico y de extrema idealización. Englobaría aquel grupo de creencias que destacan por ser las más ilógicas, imposibles y quiméricas, con expectativas extremamente elevadas. Se centra en el concepto de amor romántico como fantasía (aquel más desconectado de la realidad), conllevando una extrema idealización del amor. Se vincularía con la literatura romántica desde la visión del amor como algo mágico, así como promotor de una fuerza imparable que todo lo puede (Yela, 2003). Está vinculado al Romanticismo (finales del siglo XVIII y principios del XIX) (Branden, 2000), movimiento cultural y artístico que enfatizaba la emoción, y en donde la idealización suponía un refugio al dolor terrenal de la existencia humana, buscando con el amor una experiencia grandiosa y transcendental (no carnal) que mitificaba a la pareja, siendo común el tránsito del amor al odio (Herrera, 2019). Se relaciona con los factores "El amor encuentra el camino", "Idealización" y 
“Amor a primera vista" (Sprecher \& Metts, 1989), y "Omnipotencia" e "Irracionalidad" (Hinkle \& Sporakowski, 1975)

-Tradición: Unión del amor pasional, el sexo $y$ el matrimonio. Aglutina aquellos mitos relacionados con la vinculación amorosa normativa en Occidente (fusión del amor, el sexo $\mathrm{y}$ el matrimonio) que se establece en los siglos XIX y XX (aunque se asume como algo eterno, universal y natural), rompiéndose algunos preceptos del amor cortés (Barrón et al., 1999; Yela, 2003). Esto conllevaría un modelo de amor centrado en una vinculación pasional y amorosa exclusiva y eterna, donde el matrimonio supondría una decisión de vínculo que sólo la muerte debiera romper. Este factor se relaciona con el factor nombrado como "Uno y sólo uno" (Sprecher \& Metts, 1989) y el de "Tradicionalismo" (Hinkle \& Sporakowski, 1975).

La unión de los factores Romanticismo y Tradición se vincula con el modelo de amor romántico (Eros) de Lee (1973; 1976), basado en una fuerte intimidad, atracción física, pasión e intensidad. Muestra también una idealización notable.

Hay que señalar que la división teórica propuesta para los mitos románticos no encaja con los otros modelos de amor planteados por Lee (1973; 1976) (Ludus, Pragma y Storge). Ello es lógico teniendo en cuenta que son los únicos tres componentes no compuestos de Eros o Amor Romántico (Lee, 1973; 1976) (sí presentes en Manía y Ágape, y en el propio Eros, obviamente), lo cual refuerza la validez de contenido del modelo.

\section{Método}

\section{Participantes}

La muestra (incidental) está formada por 439 sujetos residentes en España, con orientación sexual heterosexual. Está compuesta por 70 hombres (un $15.9 \%$ ) y 369 mujeres (el $84.1 \%$ ). El $21.4 \%$ de las personas encuestadas posee (o cursa) estudios de Máster o Doctorado, un $67.9 \%$ estudios universitarios de Diplomatura, Grado o Licenciatura, y un $10.7 \%$ otro tipo de estudios (Primarios, Secundarios, Bachillerato y Formación Profesional). El rango de edad es de 19 a 63 años $(M=27.98 \mathrm{DT}=8.82)$. En la muestra que tiene pareja $(\mathrm{N}=310)$ la media de la duración de sus relaciones es de 6 años y 6 meses.

\section{Procedimiento}

La metodología de la investigación es cuantitativa y transversal. La recolección de datos se obtiene mediante un cuestionario autoadministrado. Se emplea la herramienta de encuesta virtual "Google Forms". Los ítems del instrumento fueron ordenados con el fin de evitar un efecto halo contaminador. Se insistió en la importancia de la sinceridad y se aseguró el anonimato.

\section{Instrumentos}

1) Escala de Mitos Románticos (EMRO). Evalúa 33 mitos. Se crean 99 ítems (3 ítems por mito). En una primera fase de análisis de los ítems se selecciona 1 por mito teniendo en cuenta los siguientes criterios: en primer lugar, el examen de los estadísticos descriptivos (eligiendo aquellos reactivos con medias más altas y valores de asimetría y curtosis con mejor ajuste a la curva normal) y, en segundo lugar, el análisis teórico (valorando que el ítem elegido a partir de los estadísticos descriptivos también recoge de forma rigurosa el contenido del mito). La escala resultante está compuesta por 33 ítems con un formato de respuesta tipo Likert en un rango 1-5 (grado de acuerdo con el enunciado). El instrumento puede ser consultado en el Apéndice del artículo.

2) Evaluación de la satisfacción en la pareja. Se utiliza la versión traducida (Yela, 1995) de la Relationship Assesment Scale: 7 ítems $(\alpha=.86)$ (Hendrick, 1988). Analiza el grado de satisfacción en un rango de 1 a 5 . En nuestro estudio el valor $\alpha$ es de 84 .

3) Evaluación de la legitimación del maltrato. Se parte de la versión revisada del "Inventario de Pensamientos Distorsionados sobre la Mujer y el Uso de la Violencia" (IPDMUV-R) (Echeburúa et al., 2016). Esta escala analiza creencias sobre roles de género y la supuesta inferioridad de la mujer con respeto al hombre, y la aceptación de la violencia como forma idónea para resolver conflictos. Se seleccionan 17 ítems de los 21 que conforman la escala original, siendo eliminados cuatro reactivos (ítems 13, 17, 20 y 21) que se refieren a la aceptación de la violencia en general, 
y no sólo a aquella dirigida hacia la mujer. Se presenta con un formato de respuesta tipo Likert en un rango 1-5. Se obtiene un valor $\alpha$ de .74 .

4) Evaluación de la conducta de maltrato. Se emplea una medida de 25 ítems indicadores de maltrato físico y psicológico, seleccionando: 14 ítems (número 1, 2, 4, 5, 22, 35, 39, 40, 47, 49, $50,51,52$ y 53 de la versión depurada de la escala) del APCM (Inventario de Evaluación del Maltrato a la Mujer por su Pareja) de Matud et al. (2003); 7 ítems (número 1, 9, 10, 12, 13, 14 y 17) del IAPRP (Inventario para Evaluar el Abuso Psicológico en las Relaciones de pareja) de Calvete et al. (2005); 4 ítems (número 3, 11, 13 y 27 de la versión de 27 reactivos) de la EV (Escala de Violencia) de Valdez-Santiago et al. (2006). Se generan dos escalas a partir de esta: una conformada por la violencia desde una perspectiva agente (Escala de Maltrato Agente o EMA), en la cual el encuestado responde en referencia al hecho de realizar las conductas del maltrato; y otra desde una perspectiva paciente o receptora (Escala de Maltrato Receptor o EMR), en donde se contesta en relación al hecho de haber sufrido dichas conductas por parte de la pareja. El intervalo de respuesta es de 1 a 5 evaluando la frecuencia de aparición de la conducta. Se obtiene un valor $\alpha$ de .84 en la EMA y de .89 en la EMR.

\section{Análisis de datos}

Se realiza el proceso de análisis de datos con el programa IBM SPSS Statistics 25.0.

En primer lugar, se verifica la validez estructural de la escala empleando el Análisis Factorial Confirmatorio, poniendo a prueba el modelo especificado expuesto en la introducción. Se emplea el software IBM AMOS 25.0. A la hora de seleccionar el método de estimación para el AFC, Máxima Verosimilitud (MV) suele ser el más recomendado, siendo relevante para su uso emplear muestras de elevado tamaño (superior a 300 sujetos) (Ortiz y Fernández-Pera, 2018). A pesar de que este método asume normalidad multivariada, también ha demostrado su robustez ante desviaciones de la normalidad (Ortiz \& Fernández-Pera, 2018; Schermelleh-Engel et al., 2003). En nuestro estudio, los ítems de mitos románticos incluidos en el modelo no cumplen el supuesto de normalidad (prueba de Kolmogorov-
Smirnov), pero muestran valores de asimetría y curtosis inferiores a 2 y 7 respectivamente (salvo 3 ítems con una asimetría muy próxima a 2), pudiendo considerarse aceptable su grado de compatibilidad con la curva normal (Curran et al., 1996; Iglesias-García et al., 2020). Atendiendo a las recomendaciones expuestas, se emplean el método de Máxima Verosimilitud. Se analiza también la fiabilidad del modelo a partir del Alfa del Cronbach y la correlación elemento-total corregida en cada factor, y se presentan los estadísticos descriptivos de las variables principales del estudio. Finalmente, se exponen pruebas de validez criterio a partir de la correlación de Pearson con otros constructos teóricos (tales como la ejecución y legitimación del maltrato), así como análisis de regresión.

\section{Resultados}

\section{Análisis dimensional y estructural}

A partir del AFC se pone a prueba el modelo de 4 factores (y 31 ítems) expuesto en la introducción, empleando como método de estimación principal Máxima Verosimilitud (ML) (Figura 1). El modelo está sobreidentificado ( $\mathrm{gl}>$ 0 ). Siguiendo a varias referencias (Hooper et al., 2008; Castro et al., 2021), se tienen en cuenta como índices de ajuste del modelo: $\chi^{2 / g 1}$, CFI (Comparative Fit Index), SRMR (Standardised Root Mean Square Residual) y RMSEA (Root Mean Square Error of Approximation). Se considera lo siguiente: $\chi^{2} / \mathrm{gl}$ (valores entre 1 y 3 indicarán buen ajuste); CFI (valores iguales o superiores a .90 indicarán un ajuste plausible) (Dimitrov, 2006; Hu \& Bentler, 1999); SRMR (valores inferiores a .08 se consideran óptimos); RMSEA (son válidos valores inferiores a .07 , indicando un mejor ajuste valores iguales o inferiores a .06) (Hooper et al., 2008; Hu $\&$ Bentler, 1999). El modelo refleja los siguientes valores: $p$ (.000), $\chi 2 / g l$ (2.544), CFI (.89), SRMR (.052) y RMSEA (.059). Se puede observar que sus valores son óptimos en diversos indicadores de ajuste $(\chi 2 / g l<3$; SRM $<.08$; RMSEA<.06), siendo tolerable el dato del CFI, muy próximo a .90 . Los estimadores son significativos en todos ítems $(p \leq .001)$, y las cargas son superiores a .30 en todos ellos, lo que también es un indicador de buen ajuste. 


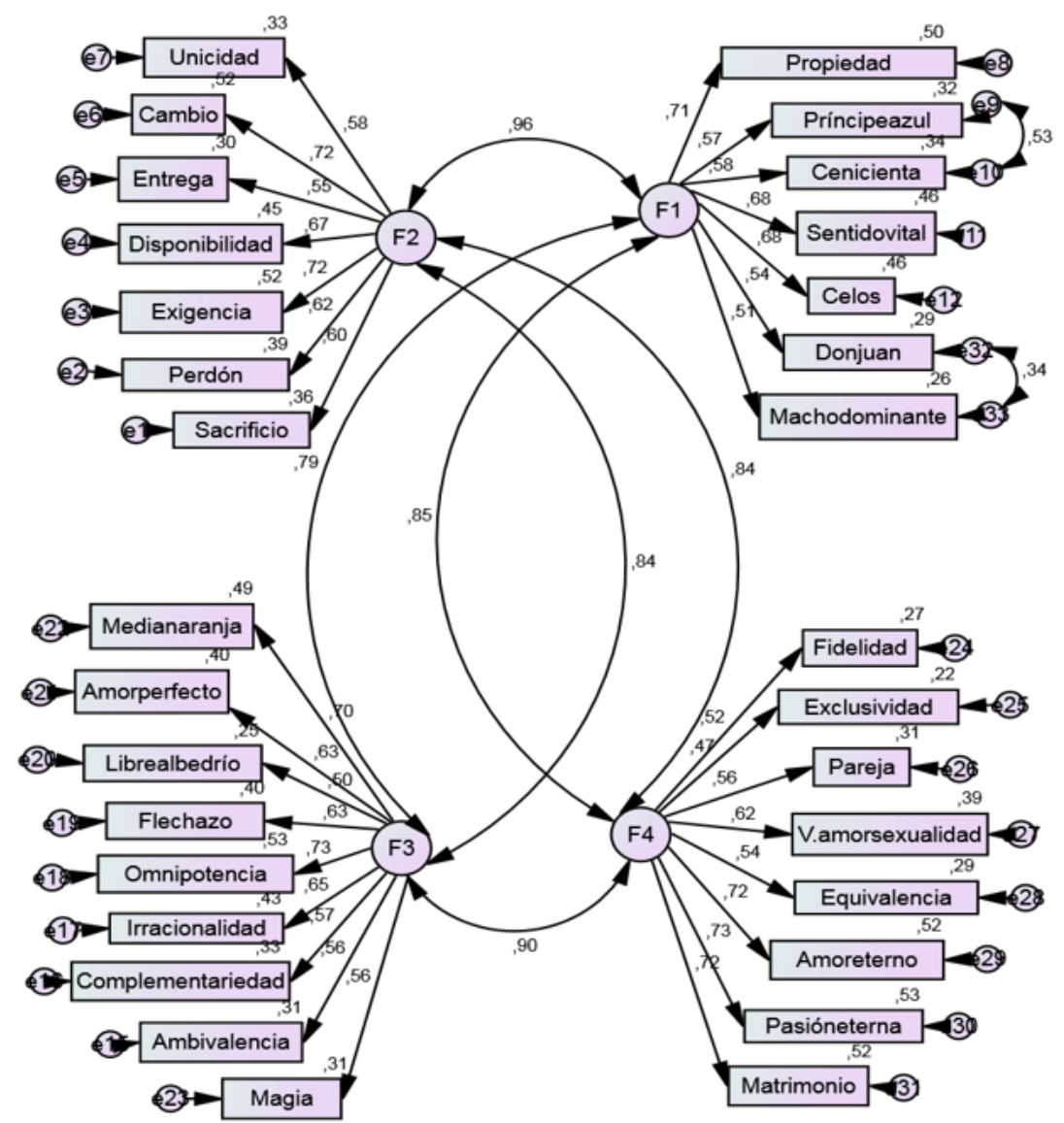

Figura 1. Análisis Factorial Confirmatorio: Modelo de 4 factores (31 ítems)

Nota. F1: Posesión (Amor controlador y celoso). F2: Abnegación (Amor de entrega y renuncia extrema). F3: Romanticismo (Amor fantástico y de extrema idealización) F4: Tradición (Unión del amor pasional, el sexo y el matrimonio).

Teniendo en cuenta la revisión de los índices de modificación, se relacionan los errores de medida de dos pares de ítems (tal como se observa en la Figura 1), siendo coherentes con la literatura referente al género y el amor romántico: el príncipe azul y la cenicienta, cuya existencia depende uno del otro (cuidar y proteger y ser cuidada y protegida); el macho dominante y el Don Juan, siendo los mitos que se refieren al modelo de hombre atrayente, basado en la masculinidad hegemónica occidental (Chafetz, 1975; Herrera, 2019). Estos cuatro ítems son los únicos que hacen referencia a diferencias de género en su enunciación, y se establece su relación, tal como se ha expuesto, bajo criterios de justificación teórica.

También se realizan correlaciones de Pearson entre los ítems de mitos románticos (con valores inferiores a .68) y los factores del modelo (con valores inferiores a .76), sin que se detecten problemas de multicolinealidad ( $r \geq .80)$ (Martínez et al., 2015).

\section{Análisis de fiabilidad: Alfa de Cronbach}

Los valores Alfa de Cronbach para cada factor de los mitos románticos, y la escala en general (compuesta por los 33 ítems), son los que siguen: Posesión (.81), Abnegación (.82), Romanticismo (.84), Tradición (.83) y EMRO o Escala de Mitos Románticos (.94).

Se obtienen valores de consistencia interna adecuados (superiores o muy próximos a .80 ), en el conjunto de la escala y en sus diferentes factores. Por otro lado, las correlaciones ítemtotal corregida en cada factor y en la puntuación global de la EMRO son siempre superiores a .30, y la fiabilidad en ningún caso aumenta al eliminar cualquiera de los ítems, por lo que todos se consideran necesarios.

\section{Análisis descriptivo}

En la Tabla 2 se muestran los resultados descriptivos de las variables principales de este estudio. Los datos revelan una muy reducida presencia de maltrato agente y receptor, una elevada satisfacción en la relación de pareja de las 
Tabla 2. Estadísticos descriptivos de las variables compuestas

\begin{tabular}{lccccccccc}
\hline & $\begin{array}{c}\text { EMRO } \\
\text { (33 ítems) }\end{array}$ & $\mathrm{T}$ & $\mathrm{R}$ & $\mathrm{A}$ & $\mathrm{P}$ & IPDMUV & RAS & EMA & EMR \\
\hline $\mathrm{n}$ & 439 & 439 & 439 & 439 & 439 & 439 & 309 & 309 & 308 \\
$\mathrm{M}$ & 1.96 & 2.39 & 2.10 & 1.76 & 1.65 & 1.38 & 4.03 & 1.06 & 1.10 \\
$\mathrm{DT}$ & .63 & .84 & .77 & .69 & .62 & .31 & .59 & .14 & .22 \\
\hline
\end{tabular}

Nota. EMRO: Escala de Mitos Románticos; T: Tradición; R: Romanticismo; A: Abngeación; P: Posesión; IPDMUV: Inventario de Pensamientos Distorsionados sobre la Mujer y el Uso de la Violencia; EMA: Escala de Maltrato Agente; EMR: Escala de Maltrato Receptor; RAS: Relationship Assesment Scale (evaluación de la satisfacción en pareja); n: Tamaño de la muestra; M: Media; DT: Desviación Típica.

Tabla 3. Estadísticos descriptivos de los ítems de la EMRO

\begin{tabular}{lccccccccccc}
\hline $\mathrm{V}$ & $\mathrm{n}$ & $\mathrm{M}$ & $\mathrm{DT}$ & $\mathrm{A}$ & $\mathrm{C}$ & $\mathrm{V}$ & $\mathrm{n}$ & $\mathrm{M}$ & $\mathrm{DT}$ & $\mathrm{A}$ & $\mathrm{C}$ \\
\hline $\mathbf{1}$ & 439 & 3.17 & 1.43 & -.26 & -1.23 & $\mathbf{1 8}$ & 439 & 1.88 & 1.11 & 1.05 & .06 \\
$\mathbf{2}$ & 439 & 2.95 & 1.29 & -.22 & -1.08 & $\mathbf{1 9}$ & 439 & 1.87 & 1.06 & .85 & -.52 \\
$\mathbf{3}$ & 439 & 2.76 & 1.41 & .16 & -1.30 & $\mathbf{2 0}$ & 439 & 1.87 & 1.11 & 1.18 & .45 \\
$\mathbf{4}$ & 439 & 2.53 & 1.30 & .32 & -1.07 & $\mathbf{2 1}$ & 439 & 1.76 & 1.01 & 1.17 & .50 \\
$\mathbf{5}$ & 439 & 2.41 & 1.22 & .54 & -.58 & $\mathbf{2 2}$ & 439 & 1.74 & .99 & 1.29 & .92 \\
$\mathbf{6}$ & 439 & 2.40 & 1.28 & .41 & -.97 & $\mathbf{2 3}$ & 439 & 1.72 & 1.02 & 1.23 & .50 \\
$\mathbf{7}$ & 439 & 2.36 & 1.01 & .53 & -.93 & $\mathbf{2 4}$ & 439 & 1.65 & .88 & 1.34 & 1.33 \\
$\mathbf{8}$ & 439 & 2.26 & 1.12 & .42 & -.78 & $\mathbf{2 5}$ & 439 & 1.59 & .88 & 1.61 & 2.53 \\
$\mathbf{9}$ & 439 & 2.16 & 1.25 & .68 & -.77 & $\mathbf{2 6}$ & 439 & 1.55 & .86 & 1.60 & 2.06 \\
$\mathbf{1 0}$ & 439 & 2.15 & 1.16 & .73 & -.43 & $\mathbf{2 7}$ & 439 & 1.54 & .80 & 1.50 & 1.91 \\
$\mathbf{1 1}$ & 439 & 2.11 & 1.02 & .41 & -.78 & $\mathbf{2 8}$ & 439 & 1.47 & .85 & 1.91 & 3.12 \\
$\mathbf{1 2}$ & 439 & 2.10 & 1.24 & .89 & -.35 & $\mathbf{2 9}$ & 439 & 1.46 & .79 & 1.99 & 4.19 \\
$\mathbf{1 3}$ & 439 & 2.08 & 1.13 & .75 & -.36 & $\mathbf{3 0}$ & 439 & 1.41 & .76 & 2.02 & 3.99 \\
$\mathbf{1 4}$ & 439 & 1.97 & 1.01 & .84 & -.20 & $\mathbf{3 1}$ & 439 & 1.33 & .70 & 2.43 & 6.10 \\
$\mathbf{1 5}$ & 439 & 1.95 & 1.20 & 1.01 & -.13 & $\mathbf{3 2}$ & 439 & 1.33 & .69 & 2.51 & 6.79 \\
$\mathbf{1 6}$ & 439 & 1.94 & 1.22 & 1.10 & .12 & $\mathbf{3 3}$ & 439 & 1.31 & .70 & 2.60 & 6.98 \\
$\mathbf{1 7}$ & 439 & 1.92 & 1.06 & 1.06 & .40 & & & & & & \\
\hline
\end{tabular}

Nota. V: Variable; n: Tamaño de la muestra; M: Media; DT: Desviación Típica; A: Asimetría; C: Curtosis; 1. Vínculo amor-sexualidad; 2. Pareja; 3. Fidelidad; 4. Libre albedrío; 5. Exclusividad; 6. Media naranja; 7. Irracionalidad; 8. Complementariedad; 9. Ambivalencia; 10. Magia; 11. Macho dominante; 12. Unicidad; 13. Equivalencia; 14. Pasión eterna; 15. Omnipotencia; 16. Amor eterno; 17. Entrega Incondicional; 18. Matrimonio; 19. Don Juan; 20. Sacrificio; 21. Propiedad; 22. Disponibilidad; 23. Sentido vital; 24. Cambio; 25. Amor perfecto; 26. Exigencia máxima; 27. Flechazo; 28. Castidad; 29. Perdón; 30. Celos; 31. Cenicienta; 32. Príncipe Azul; 33. Pecado.

Tabla 4. Correlaciones ( $\mathrm{r}$ de Pearson) del modelo con otras escalas

\begin{tabular}{lccccc}
\hline Escalas & Posesión & Abnegación & Romanticismo & Tradición & EMRO (33 ítems) \\
\hline IPDMUV & $.59^{* *}$ & $.53^{* *}$ & $.51^{* *}$ & $.49^{* *}$ & $.60^{* *}$ \\
EMA & $.36^{* *}$ & $.29^{* *}$ & $.19^{* *}$ & $.13^{*}$ & $.24^{* *}$ \\
EMR & $.26^{* *}$ & $.25^{* *}$ & $.20^{* *}$ & .08 & $.20^{* *}$ \\
RAS & -.05 & -.03 & -.02 & $.13^{*}$ & .02 \\
\hline
\end{tabular}

Nota. $* * p<.01, * p<.05$. IPDMUV: Inventario de Pensamientos Distorsionados sobre la Mujer y el Uso de la Violencia; EMA: Escala de Maltrato Agente; EMR: Escala de Maltrato Receptor; RAS: Relationship Assesment Scale (evaluación de la satisfacción en pareja); EMRO: Escala de Mitos Románticos.

personas que son encuestadas, y una postura genérica de desacuerdo con los mitos y sus factores, aunque existe un mayor acuerdo en lo referente a los factores Romanticismo y Tradición. En la Tabla 3 se exponen estadísticos descriptivos referentes a los ítems de mitos románticos.

\section{Análisis de validez criterio}

Como se aprecia en la Tabla 4, existen correlaciones significativas de la EMRO y tres de sus factores (Posesión, Abnegación y Romanticismo) con todas las medidas criterio salvo con la de satisfacción. De este modo, tanto los pensamientos sexistas y de legitimación de la violencia (IPDMUV) como el maltrato (EMA y
EMR) parecen estar relacionados de algún modo con la creencia en los mitos románticos, especialmente con el factor Posesión. El único factor de la EMRO que muestra una relación significativa con la satisfacción, y una escasa (o nula) relación con las conductas de maltrato, es "Tradición".

Se obtienen otras correlaciones significativas: EMR-EMA $(r=.79, p<.01)$, EMR-RAS $(r=-.27$, $p<.01)$, EMR-IPDMUV $(r=.19, p<.01)$, EMARAS $(r=-.22, p<.01)$, EMA-IPDMUV $(r=.25$, $p<.01)$. Los resultados muestran un valor de correlación claramente superior a los demás, referente a la relación entre el maltrato agente y el receptor. Además, estas dos variables correlacionan de forma positiva con el IPDMUV 
Tabla 5. Resumen de los resultados de la regresión por el método pasos sucesivos. VD=Maltrato Agente

\begin{tabular}{|c|c|c|c|c|c|}
\hline Variable & B & ET.B & Beta & $\mathrm{R}^{2}$ & Cambio $\mathrm{R}^{2}$ \\
\hline Paso 1 & & & & $.63 * * *$ & $.63 * * *$ \\
\hline Constante & $.52 * * *$ & .03 & & & \\
\hline EMR & $.50 * * *$ & .02 & .79 & & \\
\hline Paso 2 & & & & $.65 * * *$ & $.02 * * *$ \\
\hline Constante & $.49 * * *$ & .03 & & & \\
\hline EMR & $.47 * * *$ & .02 & .75 & & \\
\hline POSESIÓN & $.04 * * *$ & .01 & .16 & & \\
\hline Paso 3 & & & & $.66^{* * *}$ & $.01 *$ \\
\hline Constante & $.50 * * *$ & .03 & & & \\
\hline EMR & $.47 * * *$ & .02 & .75 & & \\
\hline POSESIÓN & $.05 * * *$ & .01 & .23 & & \\
\hline ROMANTICISMO & $-.02 *$ & .01 & -.10 & & \\
\hline
\end{tabular}

Nota. Valor del estadístico de contraste $\mathrm{F}$ del modelo: $\mathrm{F}(3,301)=192.05, p<.001 . \mathrm{R}^{2}=.66$ y $\mathrm{R}^{2}$ corr $=.65 . * * * p<.001, * * p<.01,{ }^{*} p<.05$. EMR: Escala de Maltrato Receptor.

Tabla 6. Resumen de los resultados de la regresión por el método pasos sucesivos. VD= Satisfacción

\begin{tabular}{|c|c|c|c|c|c|}
\hline Variable & B & ET.B & Beta & $\mathrm{R}^{2}$ & Cambio R ${ }^{2}$ \\
\hline Paso 1 & & & & $.07 * * *$ & $.07 * * *$ \\
\hline Constante & $4.81 * * *$ & .16 & & & \\
\hline EMR & $-.70 * * *$ & .15 & -.27 & & \\
\hline Paso 2 & & & & $.14 * * *$ & $.07 * * *$ \\
\hline Constante & $5.30 * * *$ & .19 & & & \\
\hline EMR & $-.71 * * *$ & .14 & -.27 & & \\
\hline EDAD & $-.02 * * *$ & .003 & -.26 & & \\
\hline Paso 3 & & & & $.16^{* * *}$ & $.02 * *$ \\
\hline Constante & $5.09 * * *$ & .20 & & & \\
\hline EMR & $-.74 * * *$ & .14 & -.28 & & \\
\hline EDAD & $-.02 * * *$ & .003 & -.26 & & \\
\hline TRADICIÓN & $.01 * *$ & .04 & .15 & & \\
\hline Paso 4 & & & & $.19 * * *$ & $.03 * *$ \\
\hline Constante & $5.35 * * *$ & .22 & & & \\
\hline EMR & $-.67 * * *$ & .14 & -.26 & & \\
\hline EDAD & $-.02 * * *$ & .003 & -.25 & & \\
\hline TRADICIÓN & $.16^{* * *}$ & .04 & .24 & & \\
\hline IPDMUV & $-.36 * *$ & .12 & -.18 & & \\
\hline
\end{tabular}

Nota. Valor del estadístico de contraste $\mathrm{F}$ del modelo: $\mathrm{F}(4,299)=17.12, p<.001 . \mathrm{R}^{2}=.19$ y R ${ }^{2}$ corr $=.18 . * * * p<001, * * p<.01$

EMR: Escala de Maltrato Receptor; IPDMUV: Inventario de Pensamientos Distorsionados sobre la Mujer y el Uso de la Violencia.

(siendo algo mayor la relación con el maltrato agente), mientras que su relación con la satisfacción es negativa (y algo superior con el maltrato receptor).

Se realizan también análisis de regresión lineal múltiple con el fin de conocer qué variables (y qué grupos de mitos) de nuestro estudio predicen el maltrato agente y la satisfacción en la pareja. Los resultados pueden ser observados en las Tablas 5 y 6 . Se emplea el método de pasos sucesivos (Stepwise). Las variables incluidas en cada modelo son: maltrato receptor, maltrato agente, satisfacción, IPDMUV, posesión, abnegación, romanticismo y tradición. En el caso del modelo que predice la satisfacción se añade también la edad como variable dependiente, al ser la única variable sociodemográfica que presenta una correlación significativa destacable $(r=-.27$, $p<.01)$ con alguna de las variables a predecir (EMA y RAS).
Todos los modelos cumplen el supuesto de independencia de los errores (prueba de Durbin Watson), así como no se detectan problemas de multicolinealidad (TOL y FIV), sin que existan correlaciones de Pearson con un valor superior o igual a .80 entre los predictores. Se cumple el tamaño de la muestra exigido (40 sujetos por predictor) para el método de pasos sucesivos en la RLM (Martínez et al., 2015).

Los resultados de los análisis de regresión señalan que, de mayor a menor orden de relevancia, las variables que predicen el maltrato agente $\left(\mathrm{R}^{2}=.66\right)$ serían: maltrato receptor (.75), Posesión (.23) y romanticismo (-.10). Para la satisfacción $\left(\mathrm{R}^{2}=.19\right)$ los predictores significativos serían los que siguen: maltrato receptor (-.26), edad (-.25), tradición (.24) y el IPDMUV (-.18).

Para los análisis que incluyen medidas de conductas de maltrato (EMR y EMA) y 
satisfacción (RAS) se emplea únicamente la submuestra que tiene pareja $(\mathrm{N}=310)$.

\section{Discusión}

En lo referente a la validez estructural de la escala, se pueden observar fuertes relaciones entre los factores, siendo las más notorias las que se dan entre Posesión y Abnegación, por un lado, y entre Romanticismo y Tradición, por otro. Los dos primeros factores parecen reflejar una cara del amor menos amable, basada en el control, la dominancia, el sacrificio y la renuncia en la pareja, que recuerda a un modelo de amor adictivo (Yela, 2006), mientras que los factores Romanticismo y Tradición muestran una cara más amable del amor (mágica, omnipotente, pasional y eterna) relacionada con el modelo de amor Eros de Lee $(1973 ;$ 1976). Según los datos, ambas caras del mito romántico estarían muy relacionadas. La cara más desagradable quizás pueda mantener a flote la pasión y la destacable idealización inherente al modelo "Eros" (otra cuestión radicaría en que ello pueda ser insano), o bien mostrar el lado más amargo del mito que es insostenible cuando desaparece el enamoramiento (Yela, 2000; 2003). Esta dicotomía en el amor podría servir como atenuante ante la violencia ejercida por el hombre en la pareja ("en ese momento no era él mismo") (Wood, 2001).

Los valores de consistencia interna a partir del Alfa de Cronbach reflejan una fiabilidad muy elevada de la EMRO (.94) así como de sus subescalas (con valores próximos o superiores a .80 ). Las cifras que reflejan otras escalas sobre mitos románticos suelen distar de los aquí obtenidos: .81 (Sprecher \& Metts, 1989) y .51 (Bosch et al., 2007).

En lo tocante a la validez criterio, tiene sentido que se hayan obtenido correlaciones significativas positivas entre la EMRO y la legitimación del maltrato (IPDMUV), en la misma línea que otro trabajo (Bonilla-Algovia \& RivasRivero, 2019). También parece coherente su conexión con las conductas de maltrato, desde la teoría que relaciona la violencia de género en la pareja (y el sexismo) con los mitos románticos (e.g., Ferrer et al., 2010), y que dicha relación no se dé con el RAS (Escala de Evaluación de las Relaciones), donde la evidencia empírica y teórica en este sentido es contradictoria (e.g., Barrón et al., 1999; Ferrer et al. 2010; Yela, 2003). El hecho de que la creencia en los mitos no esté relacionada con la satisfacción en la relación, es un dato interesante e intrigante, que merece atención futura en posteriores análisis.

Las correlaciones más elevadas entre el maltrato (en la IPDMUV y las conductas de maltrato) y los mitos se dan con Posesión, y a su vez este factor es un predictor significativo en el análisis de regresión (junto a Romanticismo y maltrato receptor) del maltrato agente, presentando un valor Beta positivo. Esto es coherente con el hecho de englobar mitos románticos basados en el control, los celos y la subordinación, algunos de ellos con cierta diferenciación de género (como Macho Dominante, Don Juan, Príncipe Azul y Cenicienta). Todo ello está relacionado con la literatura que vincula los celos con la violencia en la pareja (e.g., González Ortega et al., 2008), así como el sexismo (y la misoginia) con la violencia de género en la pareja (e.g., Bosch et al., 2013). Es de mención que la Abnegación también presenta una correlación destacable con el maltrato agente $(r=.29, p<.01)$ y receptor $(r=.25$, $p<.01)$, siendo su valor de correlación con el maltrato receptor prácticamente el mismo que con Posesión. Su vinculación con el maltrato receptor es consonante con el hecho de agrupar aquellos mitos centrados en anteponer el bienestar del otro de manera extrema, sin tener en cuenta el autocuidado, lo cual podría conllevar cierta sumisión en la pareja que se vincule al maltrato recibido. Al existir una estrecha conexión entre la abnegación y la exigencia (hacia uno mismo y la pareja, al equiparar sacrificio y esfuerzo a amor verdadero), tiene sentido que también se relacione con el maltrato agente, pudiendo esperar y demandar (incluso con violencia) el sacrificio del otro. También se podría reaccionar con violencia ante la impotencia generada por el sometimiento (en nombre de amor, sin que exista una verdadera elección personal) en la relación. Tendría sentido señalar que en una relación con cierta tendencia machista, posesiva y controladora (propia del factor Posesión) podría estar presente en mayor medida la entrega y renuncia extrema hacia la pareja en nombre del amor (inherente a la Abnegación). 
Los factores Posesión y Abnegación incluyen dos grupos de mitos que reflejan en su propia definición la cara menos amable del amor. Algunas de estas creencias se nombran en la literatura referente a los mitos románticos (e.g., De la Peña et al., 2011; Ferrer \& Bosch, 2013; García \& Casado, 2010), pero no se recogen a partir de un instrumento amparado en un estudio psicométrico.

Se obtiene una correlación directa y positiva (aunque reducida) entre el romanticismo y el maltrato agente $(r=.19, p<.01)$, mientras que en el análisis de regresión es un predictor significativo (junto a Posesión y el maltrato receptor) con valor Beta negativo (-.10) de la ejecución del maltrato. Debido a la ambivalencia y la reducida magnitud de los resultados, se requiere más investigación ulterior para poder dar entidad y una explicación rigurosa a estos datos. Es imperativo señalar que el predictor principal del maltrato agente es, con diferencia, el maltrato receptor, con un valor Beta positivo muy elevado, lo cual denota la fuerte relación entre recibir y ejercer maltrato en nuestra muestra de estudio.

Es también interesante que se obtenga una correlación significativa (aunque reducida) entre Tradición y la satisfacción en la pareja, siendo además un predictor significativo de la satisfacción en el análisis de regresión (junto al maltrato receptor, la edad y el IPDMUV). Ello podría relacionarse con el hecho de presentar aquellos mitos que más conformidad cultural presentan con Occidente (desde el modelo amoroso hegemónico que vincula sexo, amor y matrimonio) (Yela, 2000), cumpliéndose las expectativas sociales y familiares, pudiendo derivar en una mayor aceptación social. También podrían generar cierta "seguridad" al predominar en la actualidad el amor líquido: modelo de relación con escasa implicación emocional, en el que se trataría a la otra persona como mercancía que ha de estar lista para uno mismo (sin que el vínculo conlleve esfuerzo), estando sujeta a cambio si no es satisfactoria, y existiendo tendencia a la huida cuando se consume el "producto" (puesto que todo bien es perecedero) (Bauman, 2005). De igual manera, es presumible que mientras la inyección pasional esté activa, nuestro cuerpo experimente reacciones hormonales que pueden conectar con una mayor sensación de intensidad y felicidad romántica (Fisher, 1992), que desde la aceptación de la Tradición supondrían una mayor vinculación entre amor y pasión, creyendo que esta simbiosis será eterna (aunque sea un mito). Además, se asegurarían y fomentarían las inversiones que se hacen en la relación, al considerar que el vínculo será eterno, con una posible mayor implicación (Yela, 2000). También se trata del factor menos vinculado con el maltrato, siendo poco destacable su relación con el maltrato agente, y sin presentar una correlación significativa con el maltrato receptor.

La Tradición es el único predictor de la satisfacción con valor Beta positivo en el análisis de regresión, de tal manera que el recibir maltrato, la edad y el IPDMUV presentan un valor negativo. Esto denota la estrecha relación entre maltrato e insatisfacción (como parecería evidente), que a mayor edad existiría una mayor insatisfacción, y que el sexismo y la justificación del maltrato se relacionan con un menor bienestar en la pareja.

Se observa en este estudio que algunos mitos románticos se relacionan con la violencia y la insatisfacción, con lo que su apología no conllevaría seguridad y bienestar, tal como tampoco sucedería en el amor de consumo (Bauman, 2005). En este sentido, la imposibilidad de asunción de compromiso (Bauman, 2005), o la sujeción a este en base a una naturaleza del amor imposible (mito), generaría problemas en el vínculo amoroso. Buscar la seguridad en un mito es una quimera. Es importante estudiar el amor, y reflexionar sobre él, aportando conceptos (y claridad) que nos permitan entender nuestra forma de querer y nuestras necesidades, amando bajo elecciones y no sobre una "supuesta verdadera naturaleza del amor irreal", que podría conllevar frustración e impotencia.

A la par, tal como hemos visto, también es destacable que no todos los mitos se vinculan, ni lo hacen en la misma medida, con la violencia y la satisfacción en la pareja, lo cual reafirma la validez estructural de la escala y la importancia de no sólo tener en cuenta los resultados de la EMRO en su conjunto. Hay que señalar que debido a la gran relevancia del enfoque de género en la violencia en la pareja, se realizará otro trabajo que muestre las diferencias entre hombres y mujeres 
en nuestras variables de estudio y su relación. Esto también es fundamental teniendo en cuenta que la muestra empleada en este trabajo está compuesta en mayor medida por mujeres (una limitación del estudio a destacar). Es de mención que como línea futura de investigación sería relevante profundizar en la comprobación de la invarianza factorial de la EMRO en función del género y el tener o no una relación sentimental, debido al sesgo en la muestra existente en ambas variables.

En conclusión, el artículo muestra un instrumento de investigación referente a los mitos románticos con adecuadas propiedades psicométricas, un listado de ítems y mitos románticos extenso (siendo la taxonomía más amplia localizada por los autores hasta la fecha), y una división de mitos por factores consonante con la teoría y la historia del amor romántico útil para la investigación. Además, a tenor de los resultados obtenidos en este estudio, la EMRO podría ser usada como herramienta de prevención del maltrato en la pareja.

\section{Referencias}

Argyle, M. (1987). The psychology of happiness. Methuen \& Co.

Barrón, A., Martínez-Íñigo, D., De Paúl, P., \& Yela, C. (1999). Beliefs and romantic myths in Spain. The Spanish Journal of Psychology, 2(1), 64-73. https://doi.org/10.1017/S1138741600005461

Bauman, Z. (2005). Amor líquido. FCE.

Bergara, A., Riviere, J., \& Bacete, R. (2008). Los hombres, la igualdad y las nuevas masculinidades. Instituto Vasco de la Mujer. https://www.emakunde.euskadi.eus/contenido s/informacion/gizonduz_kanpainak/es_def/adj untos/guia_masculinidad_cas.pdf

Bonilla-Algovia, E., \& Rivas-Rivero, E. (2019). Creencias distorsionadas sobre la violencia contra las mujeres en docentes en formación de Colombia. Revista Colombiana de Educación, 77, 87-106. https://doi.org/10.17227/rce.num77-9571

Borrajo, E., Gámez-Guadix, M., \& Calvete, E. (2015). Justification beliefs of violence, myths about love and cyber dating abuse. Psicothema, 27(4), 327-333.

https://doi.org/10.7334/psicothema2015.59

Bosch, E., Ferrer, V. A., García, M. E., Ramis, M. C., Mas, M. C., Navarro, C., \& Torrens, G. (2007). Del mito del amor romántico a la violencia contra las mujeres en la pareja. Estudios e Investigaciones, Instituto de la Mujer.

https://www.researchgate.net/publication/397 12224_Del_mito_del_amor_romantico_a_la_ violencia_contra_las_mujeres_en_la_pareja

Bosch, E., Ferrer, V. A., Ferreiro, V., \& Navarro, C. (2013). La violencia contra las mujeres. Anthropos.

Branden, N. (2000). La Psicología del Amor Romántico. Paidós Ibérica.

Calvete, E., Corral, S., \& Estévez, A. (2005). Desarrollo de un inventario para evaluar el abuso psicológico en las relaciones de pareja. Clínica y Salud, 16(3), 203-221. http://www.redalyc.org/articulo.oa?id=180617 759001

Castro, R., Vargas, E., Núñez, S. M., Callejas, J. E., \& Musitu, G. (2021). Análisis Psicométrico de la Escala de Relaciones Intrafamiliares. Revista Iberoamericana de Diagnóstico y Evaluación - e Avaliação Psicológica, 58(1), 19-33. https://doi.org/10.21865/RIDEP58.1.02

Chafetz, J. S. (1975). Masculine/feminine or human: An overview of the sociology of sex roles. Peacock.

Chung, D. (2005). Violence, control, romance and gender equality: Young women and heterosexual relationships. Women's Studies International Forum, 28, 445-455. https://doi.org/10.1016/j.wsif.2005.09.005

Cruz, C. (2018). El amor romántico, los estereotipos de género y su relación con la violencia de pareja. Aportaciones a la Psicología Social, 4, 459-474.

https://www.researchgate.net/publication/328 346997_El_amor_romantico_los_estereotipos _de_genero_y_su_relacion_con_la_violencia_ de_pareja

Curran, P. J., West, S. G., \& Finch, J. F. (1996). The robustness of test statistics to nonnormality and specification error in 
confirmatory factor analysis. Psychological Methods, 1(1), 16-29.

https://psycnet.apa.org/doi/10.1037/1082989X.1.1.16

De la Peña, E. M., Ramos, E., Luzón, J. M., \& Recio, P. (2011). Sexismo y Violencia de Género en la juventud andaluza. Instituto Andaluz de la Mujer. http://www.juntadeandalucia.es/iam/catalogo/ doc/iam/2011/143337353.pdf

De Rougemont, D. (1972). Los mitos del amor. Kairós. 1999.

Dimitrov, D. (2006). Comparing groups on latent variables: A structural equation modeling approach. Work, 26, 429-436.

https://www.researchgate.net/publication/699 6484_Comparing_groups_on_latent_variables _A_structural_equation_modeling_approach

Echeburúa, E., \& Fernández-Montalvo, J. (1997): Tratamiento cognitivo-conductual de hombres violentos en el hogar: un estudio piloto. Análisis y Modificación de Conducta, 23, 355384.

https://www.researchgate.net/publication/234

756556_Tratamiento_cognitivo-

conductual_de_hombres_violentos_en_el_hog ar_un_estudio_piloto

Echeburúa, E., Amor, P. J., Sarasua, B., Zubizarreta, I., \& Holgado, F. P. (2016). Inventario de Pensamientos Distorsionados sobre la Mujer y el Uso de la ViolenciaRevisado (IPDMUV-R). Anales de Psicología, 32(3), 837-846.

https://scielo.isciii.es/scielo.php?script=sci_art text\&pid=S0212-97282016000300025

Ferrer, V. A., Bosch, E., \& Navarro, C. (2010). Los mitos románticos en España. Boletín de Psicología, 99, 7-31.

https://www.researchgate.net/publication/463

11908_Los_mitos_romanticos_en_Espana

Ferrer, V., \& Bosch, E. (2013). Del amor romántico a la violencia de género. Para una coeducación emocional en la agenda educativa. Revista de Currículum y Formación del Profesorado, 17(1), 105-122. http://www.ugr.es/ recfpro/rev171ART7.pdf

Ferreira, G. B. (1995). Hombres Violentos, Mujeres Maltratadas: Aportes a la Investigación y Tratamiento de Un Problema Social. Sudamericana.
Fisher, H. (1992). Anatomía del amor. Historia natural de la monogamia, el adulterio y el divorcio. Anagrama.

Fundación Mujeres (2011). Los mitos del amor romántico y prevención de la violencia de género. Boletín FM, 93, 7-10.

http://www.fundacionmujeres.es/files/attachm ents/Documento/46001/image/_BOLETIN\%2 0FM\%2093.pdf

García Selgas, F. J., \& Casado Aparicio, E. (2010). Violencia en la pareja: Género y vínculo. Talasa Ediciones.

González-Ortega, I., Echeburúa, E., \& De Corral, P. (2008). Variables significativas en relaciones violentas en parejas jóvenes. Psicología Conductual, 16 (2), 207-225. https://www.uv.mx/cendhiu/files/2012/09/Var iablespsic.manoella.pdf

Hendrick, S. S. (1988). A generic measure of relationship satisfaction. Journal of Marriage and the Family, 50(1), 93-98.

https://psycnet.apa.org/doi/10.2307/352430

Herrera, C. (2015). Otras formas de quererse son posibles: Lo romántico es político. En (h)amor (pp. 95-125). Continta me tienes.

Herrera, C. (2019). Hombres que ya no hacen sufrir por amor: Transformando masculinidades. Catarata.

Hinkle, D. E., \& Sporakowski, M. J. (1975). Attitudes toward love: A reexamination. Journal of Marriage and the Family, 37(4), 764-767. https://doi.org/10.2307/350827

Hooper, D., Coughlan, J., \& Mullen, M. R. (2008). Structural equation modelling: Guidelines for determining model fit. The Electronic Journal of Business Research Methods, 6(1), 53-60.

https://www.researchgate.net/publication/254 742561_Structural_Equation_Modeling_Guid elines_for_Determining_Model_Fit

Hu, L., \& Bentler, P. M. (1999). Cutoff criteria for fit indexes in covariance structure analysis: Conventional criteria versus new alternatives. Structural Equation Modeling: A Multidisciplinary Journal, 6, 1-55. https://doi.org/10.1080/10705519909540118

Iglesias-García, M. T., Urbano-Contreras, A., \& Martínez-González, R. A. (2020). Escala de Frecuencia y Respuesta a los Conflictos de Pareja: Fiabilidad y Validez. Revista 
Iberoamericana de Diagnóstico y Evaluación - e Avaliação Psicológica, 56(3), 45-57. https://doi.org/10.21865/RIDEP56.3.04

Knox, D. H., \& Sporakowski, M. J. (1968). College students attitudes toward love. Journal of Marriage and the Family, 30, 638642.

https://psycnet.apa.org/doi/10.2307/349508

Lee, J. A. (1973). Colours of love: An exploration of the ways of loving. New Press

Lee, J. A. (1976). Lovestyles. J. M. Dent \& Sons.

Lelaurain, S., Fonte, D., Giger, J. C., Guignard, S., \& Lo Monaco, G. (2018). Legitimizing intimate partner violence: The role of romantic love and the mediating effect of patriarchal ideologies. Journal of Interpersonal Violence, 1-18. http://dx.doi.org/10.1177/0886260518818427

Martínez, R., Chacón, J. C., \& Castellanos, M. A. (2015). Análisis de datos en Psicología y Ciencias de la Salud (Volumen II). EOS.

Matud, M. P., Carballeira, M., \& Marrero, R. J. (2003). Validación de un inventario de maltrato a la mujer por su pareja: El APCM. Psicopatología Clínica, Legal y Forense, 3(1), 5-17.

http://www.redalyc.org/articulo.oa?id=337303 02

Ortiz, M. S., \& Fernández-Pera, M. (2018). Modelo de ecuaciones estructurales: Una guía para ciencias médicas y ciencias de la salud. Terapia Psicológica, 36(1), 47-53. https://scielo.conicyt.cl/pdf/terpsicol/v36n1/07 18-4808-terpsicol-36-01-0051.pdf

Papp, L. J., Liss, M., Erchull, M. J., Godfrey, H., \& Waaland-Kreutzer, L. (2017). The dark side of heterosexual romance: Endorsement of romantic beliefs relates to intimate partner violence. Sex Roles, 76(1-2), 99-109. https://psycnet.apa.org/doi/10.1007/s11199016-0668-0

Quinteros, A., \& Carbajosa, P. (2008). Hombres Maltratadores. Grupo 5.

Rodríguez, Y., Lameiras, M., Carrera, M. V., \& Vallejo, P. (2013). La fiabilidad y validez de la escala de mitos hacia el amor: Las creencias de los y las adolescentes. Revista de Psicología Social, 28(2), 157-168. https://doi.org/10.1174/021347413806196708
Sanpedro, P. (2005). El mito del amor y sus consecuencias en los vínculos de pareja. Disenso, 45.

https://www.aldarte.org/comun/imagenes/doc umentos/Pilar\%20Sanpedro-

amor\%20rom\%E1ntico.pdf

Sharpe, D., \& Taylor, J. K. (1999). An examination of variables from a socialdevelopmental model to explain physical and psychological dating violence. Canadian Journal of Behavioural Science, 31(3), 165175.

https://psycnet.apa.org/doi/10.1037/h0087085

Schermelleh-Engel, K., Moosbrugger, H., \& Müller, H. (2003). Evaluating the fit of structural equation models: Tests of significance and descriptive goodness-of-fit measures. Methods of Psychological Research Online, 8, 23-74.

https://www.researchgate.net/publication/251 060246_Evaluating_the_Fit_of_Structural_Eq uation_Models_Tests_of_Significance_and_D escriptive_Goodness-of-Fit_Measures

Solomon, R. C. (1988). About love. Simon \& Schuster.

Sprecher, S., \& Metts, S. (1989). Development of the Romantic Beliefs Scales and examinations of the effects of gender and gender-role orientation. Journal of Social and Personal Relationships, 6, 387-411.

https://psycnet.apa.org/doi/10.1177/02654075 89064001

Sprecher, S., \& Metts, S. (1999). Romantic beliefs: Their influence on relationships and patterns of change over time. Journal of Social and Personal Relationships, 16(6), 834-851.

https://doi.org/10.1177\%2F0265407599166009

Tenorio, N. (2012). Repensando el amor y la sexualidad: Una mirada desde la segunda modernidad. Sociológica, 27(76), 7-52.

http://www.scielo.org.mx/pdf/soc/v27n76/v27 n76a1.pdf

Valdez, R., Híjar, M. C., Salgado, V. N., Rivera, L., Avila, L., \& Rojas, R. (2006). Escala de violencia e índice de severidad. Salud Pública de México, 48, 221-231.

https://www.redalyc.org/pdf/106/10604802.pdf

Vannier, S. A., \& O'Sullivan, L. F. (2017). Passion, connection, and destiny: How 
romantic expectations help predict satisfaction and commitment in young adults' dating relationships. Journal of Social and Personal Relationships, 34(2), 235-257. https://doi.org/10.1177\%2F0265407516631156

Vasallo, B. (2015). Ruptura de monogamia: ¿Reforma o revolución? En (h)amor (pp. 915). Continta me tienes.

Wood, J. T. (2001). The normalization of violence in heterosexual romantic relationship: Women's narratives of love and violence. Journal of Social and Personal Relationships, 18, 239-261.

https://doi.org/10.1177\%2F0265407501182005

Yela, C. (1995). Análisis psicosociológico del comportamiento amoroso. (Tesis Doctoral). UCM.

Yela, C. (2000). El amor desde la Psicología social: Ni tan libres ni tan racionales. Pirámide.

Yela, C. (2003). La otra cara del amor: Mitos, paradojas y problemas. Encuentros en la Psicología Social, 1(2), 263-267.

Yela, C. (2006). Del amor adictivo. Cuaderno de Ponencias del I Encuentro Profesional sobre Dependencias Sentimentales, 1-6. http://www.institutospiral.com/cursosysemina rios/encuentrods/resumenes/Carlos\%20Yela.p df

Zamora, R., Muñoz-Cobos, F., Burgos, M. L., Carrasco, A., Martín, M. L., Ortega, I., Río, J., \& Villalobos, M. (2012). Modelo de estadios de cambio: Compatibilidad con relatos biográficos de mujeres que sufren violencia doméstica. Anales de Psicología, 28(3), 805822.

https://doi.org/10.6018/analesps.28.3.156081 


\section{Apéndice}

\section{Listado de 33 ítems ordenados por mitos y el modelo de 4 factores}

\section{Romanticismo (Amor fantástico y de extrema idealización) (9 ítems)}

Mito de la media naranja: En alguna parte existe alguien con quien encajas/encajarías perfectamente (tu "media naranja" o "alma gemela").

Mito de la omnipotencia: El amor verdadero lo puede todo.

Mito del libre albedrío: Mis sentimientos amorosos sólo dependen de mí y de la persona a la que amo.

Mito del flechazo: El hecho de enamorarse a primera vista hará más probable que la relación tenga éxito en el futuro.

Mito de la irracionalidad: El amor es ciego y responde a motivos que el ser humano no es capaz de comprender.

Mito del amor perfecto: Si encuentro a mi pareja ideal todo será perfecto en nuestra relación.

Mito de la magia romántica: Amor verdadero supone mirar a tu pareja a los ojos y saber lo que está pensando y sintiendo.

Mito de la ambivalencia romántica: Amor y odio son dos caras de la misma moneda, entre uno y otro hay tan solo un paso.

Mito de la complementariedad: Como dice el dicho, los opuestos se atraen porque se complementan.

\section{Tradición (Unión del amor pasional, el sexo y el matrimonio) (8 ítems)}

Mito de la pareja: La pareja es algo natural. En todas las épocas y culturas el ser humano ha tendido por naturaleza a emparejarse.

Mito de la fidelidad: Si uno tiene sexo con otra persona distinta a su pareja es que no existe verdadero amor hacia su pareja.

Mito exclusividad: No se puede estar verdaderamente enamorado de dos personas a la vez.

Mito de la equivalencia: En el fondo "amar" y "estar enamorado" es realmente la misma cosa: no se puede amar de verdad sin estar enamorado.

Mito del matrimonio/convivencia: El amor romántico debe conducir al matrimonio/convivencia.

Mito del amor eterno: Una relación amorosa verdadera debe perdurar toda la vida.

Mito de la pasión eterna (perdurabilidad): La pasión amorosa, si es verdadera, dura toda la vida.

Mito del vínculo amor-sexualidad: El amor y la sexualidad son en el fondo dos caras de la misma moneda por lo que el sexo es mucho mejor cuando hay amor.

\section{Abnegación (Amor de entrega y renuncia extrema) (7 ítems)}

Mito del cambio: Si de verdad quieres a tu pareja no te importa cambiar tus hábitos, intereses o forma de ser para complacerla.

Mito de la entrega incondicional: Si existe verdadero amor se debe apoyar a la pareja pase lo que pase, cualquier cosa que esta haga.

Mito de la exigencia máxima: En una relación amorosa se debe intentar complacer en todo a la pareja.

Mito del sacrificio: Amor y sacrificio van unidos de la mano, no en vano uno debe renunciar parcialmente a su intimidad, su espacio, su tiempo, sus hobbies, etc.

Mito de la unicidad: Si hay verdadero amor, no debe haber ningún secreto entre la pareja, por pequeño que sea.

Mito del perdón absoluto: Creo que debo perdonar a mi pareja por cualquier error que pueda cometer, ya que me quiere, y alguien te ama nunca te haría daño intencionadamente.

Mito de la disponibilidad inmediata: Si alguien te quiere de verdad estará disponible para ti en todo momento. 
Posesión (Amor controlador y celoso) (7 items)

Mito del macho dominante: A las mujeres les atraen los hombres dominantes.

Mito del príncipe azul: La realización/felicidad del hombre depende en gran medida de su unión con alguien a quien cuidar y proteger.

Mito de la cenicienta: La realización/felicidad de la mujer depende en gran medida de su unión con alguien que la cuide y proteja.

Mito de Don Juan: Por lo general a las chicas les atraen los rompecorazones por el deseo que desprenden.

Mito de la propiedad: Cuando estás enamorado es normal decir o sentir "eres mío/a" o "soy tuyo/a".

Mito del sentido vital: La pareja es algo fundamental para dar sentido a la vida.

Mito de los celos: En el fondo los celos son un signo de amor; si no existen celos no hay verdadero amor.

Mitos no incluidos en el modelo (2 ítems)

Mito de la castidad: Un excesivo interés sexual, antes de formalizar la relación, indica que no existe verdadero amor.

Mito del pecado: La sexualidad no es moralmente correcta si no existe amor entre sus actores. 